This item was submitted to Loughborough's Research Repository by the author.

Items in Figshare are protected by copyright, with all rights reserved, unless otherwise indicated.

\title{
Seat belt designs to protect pregnant vehicle occupants
}

PLEASE CITE THE PUBLISHED VERSION

http://dx.doi.org/10.2174/2212797611003010001

\section{PUBLISHER}

(c) Bentham Science Publishers

\section{VERSION}

AM (Accepted Manuscript)

\section{PUBLISHER STATEMENT}

This work is made available according to the conditions of the Creative Commons Attribution-NonCommercialNoDerivatives 4.0 International (CC BY-NC-ND 4.0) licence. Full details of this licence are available at: https://creativecommons.org/licenses/by-nc-nd/4.0/

\section{LICENCE}

CC BY-NC-ND 4.0

\section{REPOSITORY RECORD}

Acar, B. Serpil, and Volkan Esat. 2019. "Seat Belt Designs to Protect Pregnant Vehicle Occupants". figshare. https://hdl.handle.net/2134/25648. 


\title{
Seat Belt Designs to Protect Pregnant Vehicle Occupants
}

\author{
B. Serpil Acar and Volkan Esat \\ Department of Computer Science, Research School of Informatics, \\ Loughborough University, Leicestershire, LE11 3TU, UK
}

\begin{abstract}
Various restraint systems to protect vehicle occupants in case of an accident have been specifically designed for pregnant women and the ideas are filed for patents. The concepts cover a wide range of designs; from 'add-on' to standard 3-point seat belt solutions to relatively complex mechatronics applications. Auxiliary tools and equipments to offer lap belt solutions constitute the majority of the reviewed patents. Designs also vary according to their working principles. Some designs exclusively focus on the lap belt part of the seat belt, whereas some others attempt to resolve the problem from a broader perspective, offering overall seat belt solutions with or without the use of standard seat belt. In this article around forty patented ideas on seat belt designs for pregnant women are reviewed, classified and presented, highlighting the working principles and inventors' claims.
\end{abstract}

Keywords: Seat belt, pregnant occupant, vehicle crash, injury prevention, lap belt \& shoulder belt.

\section{INTRODUCTION}

In the past couple of decades, pregnant women's involvement in road vehicle accidents, and thus, pregnant women's safety and injury prevention have become an important topic in biomechanics, bioengineering and automotive design fields due to various factors such as increasing number of women driving, and increasing number of miles driven per women [1]. Recent statistics reveal that around $7 \%$ of all pregnancies are affected by trauma [2] and motor-vehicle accidents are the leading cause of traumatic fetal mortality worldwide [3].

According to recent statistics, in the UK alone there are approximately 750,000 pregnant women each year all of which are likely to be vehicle occupants during some or all stages of their pregnancy [4-6]. In the United States an estimated figure of around 130,000 women in the second half of pregnancy are involved in car accidents each year, around 30,000 of which will sustain treatable injuries whereas approximately 160 will die. Amongst the survivors, fetal loss inevitably occurs for 300-3800 pregnant women [7].

Research on pregnant women's road traffic issues has shown that correctly positioned seat belts play a important role in improving the safety of pregnant women and their fetuses [8-11]. Acar and Weekes reported that the existing seat belts are by far the most significant complaint reported by pregnant women [12]. Their research has revealed that only $13 \%$ of the pregnant women in the UK had the entire seat belt correctly positioned following the Department for Transport (DfT) guidelines for pregnant women, which briefly states that "The lap belt should go across the hips, fitting comfortably under the bump, while the diagonal strap should be placed between the breasts and around the bump."

*Address correspondence to these authors at the Department of Computer Science, Research School of Informatics, Loughborough University, Leicestershire, LE11 3TU, UK; Tel: +44-1509-635700;

E-mails: b.s.acar@lboro.ac.uk,v.esat@lboro.ac.uk
Department for Transport, UK published a leaflet for pregnant occupants entitled 'Buckle up for baby and you' about the importance of wearing the seat belt and wearing it correctly. An electronic brochure is also included in the DfT website, where the authors' team in Loughborough is acknowledged for its research [13]. Correct positioning rates appear to be even lower in other parts of the world. The results also exhibited that even the correctly positioned seat belt may lose its initial correct position soon after pregnant women start driving [14]. The car impact simulations and analyses from the 'Expecting' computational pregnant driver modelling research conducted by Acar et al have also shown the advantages of wearing the seatbelts correctly by investigating the strains at placental location, abdominal deflections and fetal head contact forces [15].

In order to tackle the safety issues concerning pregnant women as car drivers and passengers, restraint systems have been designed specifically for them and the ideas are filed for patents by various inventors across the globe. This article reviews and presents a classification for the patented ideas on seat belt designs for pregnant women, highlighting the working principles and inventors' claims.

\section{CLASSIFICATION OF SEAT BELT DESIGNS FOR PREGNANT OCCUPANTS}

The concepts reviewed in this article cover a wide range of designs; from various 'add-on' (to standard 3-point seat belt) solutions to relatively complex mechatronics applications. Auxiliary tools and equipments to offer lap belt solutions constitute the majority of the reviewed patents. Designs also vary according to their working principles. Some designs exclusively focus on the lap belt part of the seat belt, whereas some others attempt to resolve the problem from a broader perspective, offering overall seat belt solutions with or without the use of standard seat belt.

The characteristics of around forty patents are classified into two main groups to consider the underlying design features: 'Designs Using Standard 3-Point Seat Belt' and 
'Designs Excluding Standard 3-Point Seat Belt'. The former group, namely, designs including the standard 3-point seat belt system in contemporary vehicles as part of the design, constitutes the majority of the available patents. The latter group in theory has the advantage of much broader design possibilities; however the number of ideas patented is considerably lower than the former group.

The Designs Using Standard 3-Point Seat Belt group is classified into four subgroups taking their area of application and working principles into consideration. These subgroups are:

\section{Lap / Thighs Supporting}

\section{Shoulder / Torso Supporting}

3. Combined Lap \& Shoulder/Abdomen Protecting

\section{Other Auxiliary Solutions.}

Among these subgroups, patents in the Lap / Thighs Supporting Designs comprises majority of the reviewed solutions within the Designs Using Standard 3-Point Seat Belt group.

\subsection{Designs Using Standard 3-Point Seat Belt}

Many conceptual designs have been produced for standard 3-point seat belts, which are currently used in almost all road vehicles. The designs are usually add-on type applications that are claimed to bring additional safety and/or comfort to the pregnant occupant. The patents for this group are summarised under the aforementioned four subgroups.

\subsubsection{Lap / Thighs Supporting Designs}

An inappropriately worn lap belt riding over the 'bump' causes discomfort and anxieties about safety to the pregnant occupant [13]. Lap/thighs supporting designs concentrate on the lap belt section of the 3-point seat belt. Almost all of the patents in this group seem to have designs to prevent the lap belt from riding towards up the abdomen during driving.

One of the earlier typical designs in this group has been patented by Kruse in 1991 [16]. The inventor suggested a seatbelt positioning assembly as illustrated in Fig. (1) for positioning the lap belt along the lower abdominal region of a pregnant person. The design involves a seat pad placed on the seat pan of the automobile, which is secured by a securing strap fastened around the seat back portion. The assembly device incorporates a sleeve, which is fitted along a portion of the length of the lap belt with a pair of positioning straps connected to and extending from the seat pad. The straps are adjusted for attachment with the bottom edge of the sleeve. The inventor claims that the device pulls the seatbelt down to a position extending along the lower abdominal region of the pregnant person substantially below the abdomen.

A similar design by McGlothlin and Fagan in 1997 uses a device with a top and a bottom member, and a fastener between them in order to maintain the lap belt portion in a downward direction on the pelvic bones of the pregnant occupant as shown in Fig. (2) [17]. In this adjustable device, the top member is looped around the seat belt whereas the bottom member is fixed on the underside of the seat pan. The working principle is similar to the previous device; a stiff
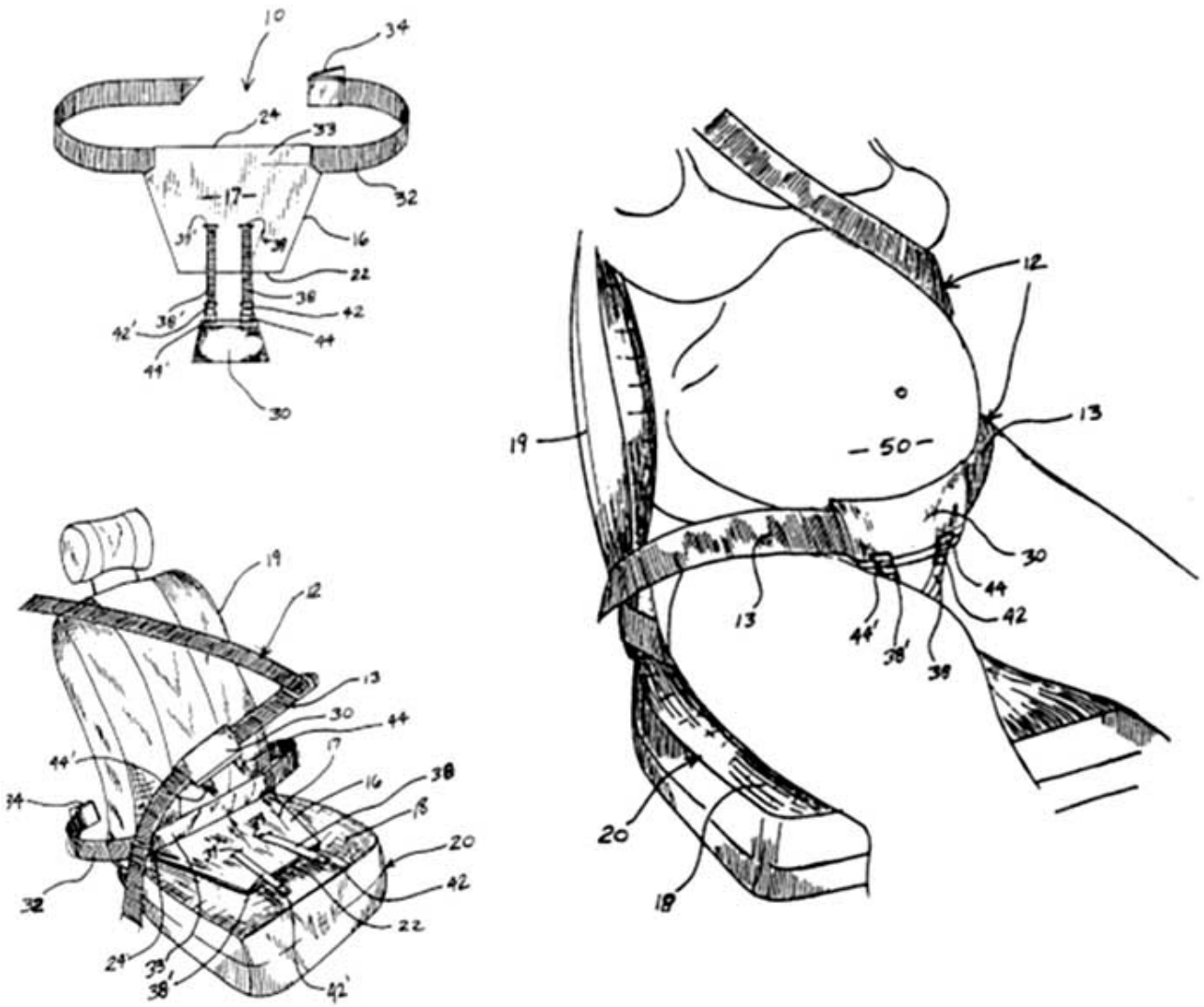

Fig. (1). Seat belt positioning assembly for a pregnant person (for the complete description of the numbers, see [16]). 

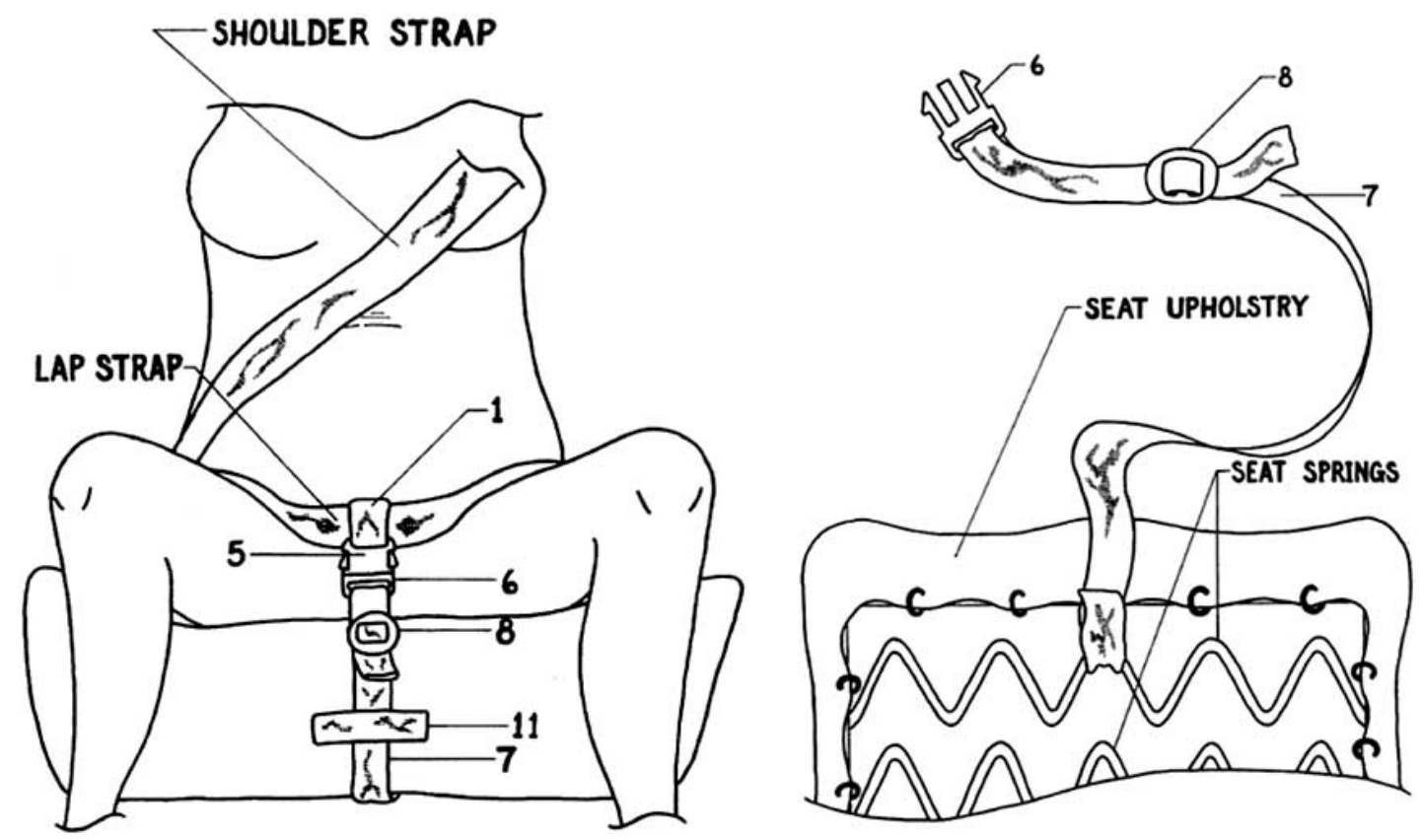

Fig. (2). Safety system attached to seat belt (for the complete description of the numbers, see [17]).

and adjustable fastener pulling the lap belt downwards, away from the abdomen. Difference is that the bottom member is fixed to the seat whereas the first one is attached to the pad, which is not fixed.

In 2005, Nerette patented a 'pregnancy seatbelt' with facility of quick release with a seat mat placed on the seat pan as shown in Fig. (3) [18]. The mat is secured on the seat by an elongated securing strap fastened around the lower portion of the vehicle seat back. Criss-cross elastic straps sewn into the seating mat and a VELCRO hook and loop material attachment, which join both straps are unique in this design. The working principle appears that the hook and loop material pulls the straps extending upwards and the lap belt portion downwards in position over the hypogastric area of the lower abdominal region of the pregnant women [18]. The inventor claims that the seat mat is designed to be soft and will not be affected by the temperature inside the vehicle. The hook and loop material attachment has a unique "V" shape, which joins the criss-cross elastic straps and is thought to be in an anatomical shape to be a more comfortable attachment that fits in between a pregnant woman's legs. The inventor also claims that the securing straps which are fitted with plastic quick release buckles, would allow others to use the car seat without using the pregnancy seat belt.

A recent design by Zlojutro in 2007 uses a similar concept of keeping the lap belt in a lowered position with a different design as illustrated in Fig. (4) [19]. The 'attachment' has an anchor portion in the form of a loop fitted around the head restraint and extends downwards along the seat back. The other end of the attachment device is secured and adjusted on the lap belt, pulling it downwards as the pregnant occupant sits on the seat. Different versions of the attachment strap which may be directed along the rear side of the seat back rather than the front side and equipped with a cushion material to provide improved comfort where the attachment meets and wraps the lap belt are patented. All versions of the device are shown in Fig. (4).

The working principle of pulling the lap belt further downwards and securing the lap portion on the pelvic region has been used through varying designs also by various other inventors around the world. Some seat belt devices use the mat idea on the seat with different attaching mechanisms to the lap belt [20-26] whereas some other designs make use of the seat belt auxiliary devices or tools usually to envelope the lap belt in their hook or attachment sections [27-30].

A seat belt auxiliary device that has been patented by Tsutomu in 2002, not only pulls in the lap belt between the legs, but also from the sides of each leg as illustrated in Fig. (5) [31]. In this design, in addition to the standard buckle and tongue of the 3-point seat belt provided on the vehicle, other buckles are present, by which the lap portion of the seatbelt can be pulled downwards.

Another concept developed by Harper et al. in 2001, which works by using the lap portion of the standard 3-point seat belt, consists of a lap pillow and a positioner for the lap belt, and an additional cushioning element attached to the device at the upper edge of the lap belt for padding the upper edge as seen in Fig. (6) [32]. The inventors claim that comfort is enhanced and the lap belt is pulled downwards into its proper position across the pelvis.

The cushion type devices have also been developed by other inventors. In 2003, Von Bergen has developed a protective cushion for the lap belt, which is located between the abdomen of the woman and the lap belt of a conventional three-point seat belt system [33]. In this design, the lap belt is fastened on the outer side of the cushion. It is reported that the structure of the cushion is partly elastic to avoid any discomfort on the abdomen when wearing the seat belt. It is claimed that it also provides a positive protection during a car crash. Another solution has been patented by Akihiro and Jun in 2006 which comprises of a cushion that is placed on 

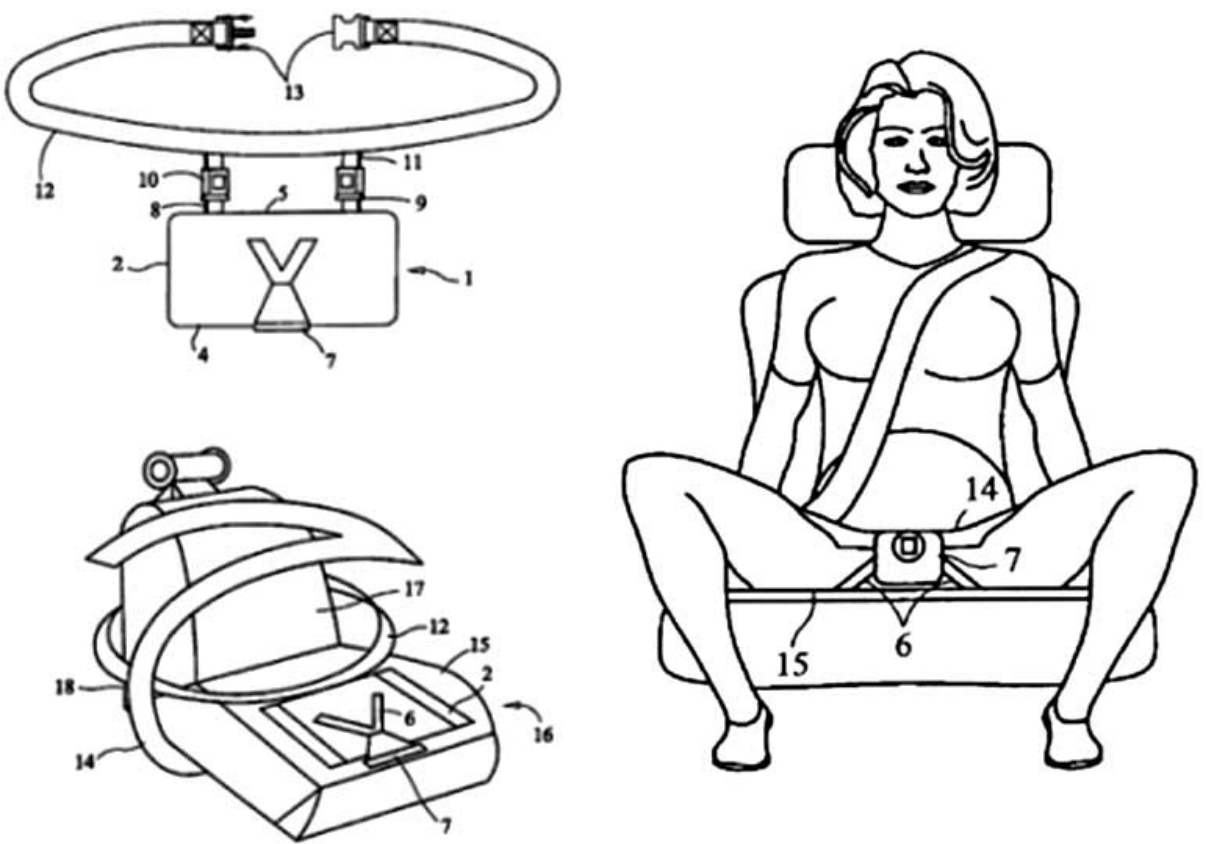

Fig. (3). Pregnancy seat belt (for the complete description of the numbers, see [18]).

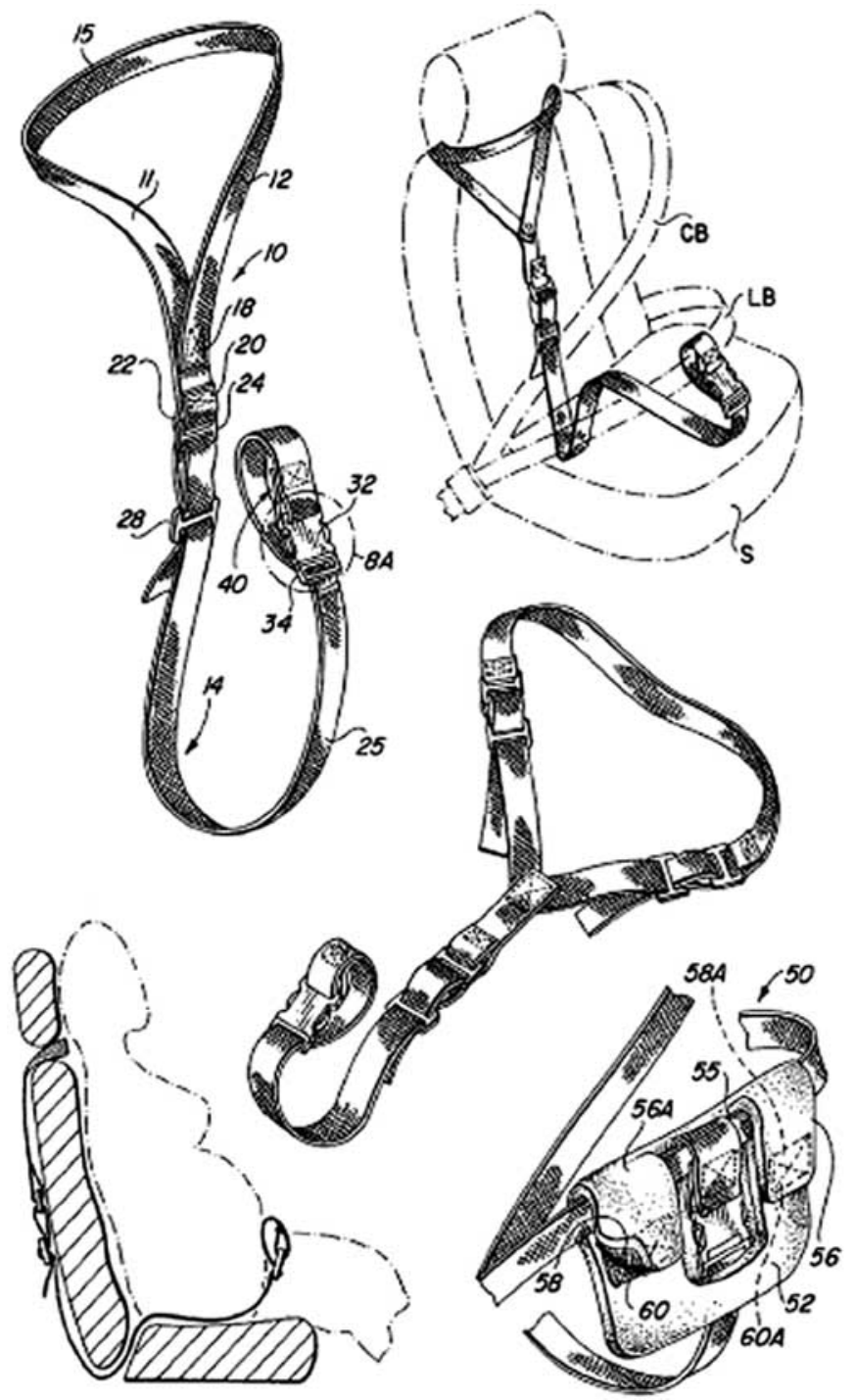

Fig. (4). Seat belt attachment for use by pregnancy women (for the complete description of the numbers, see [19]). 

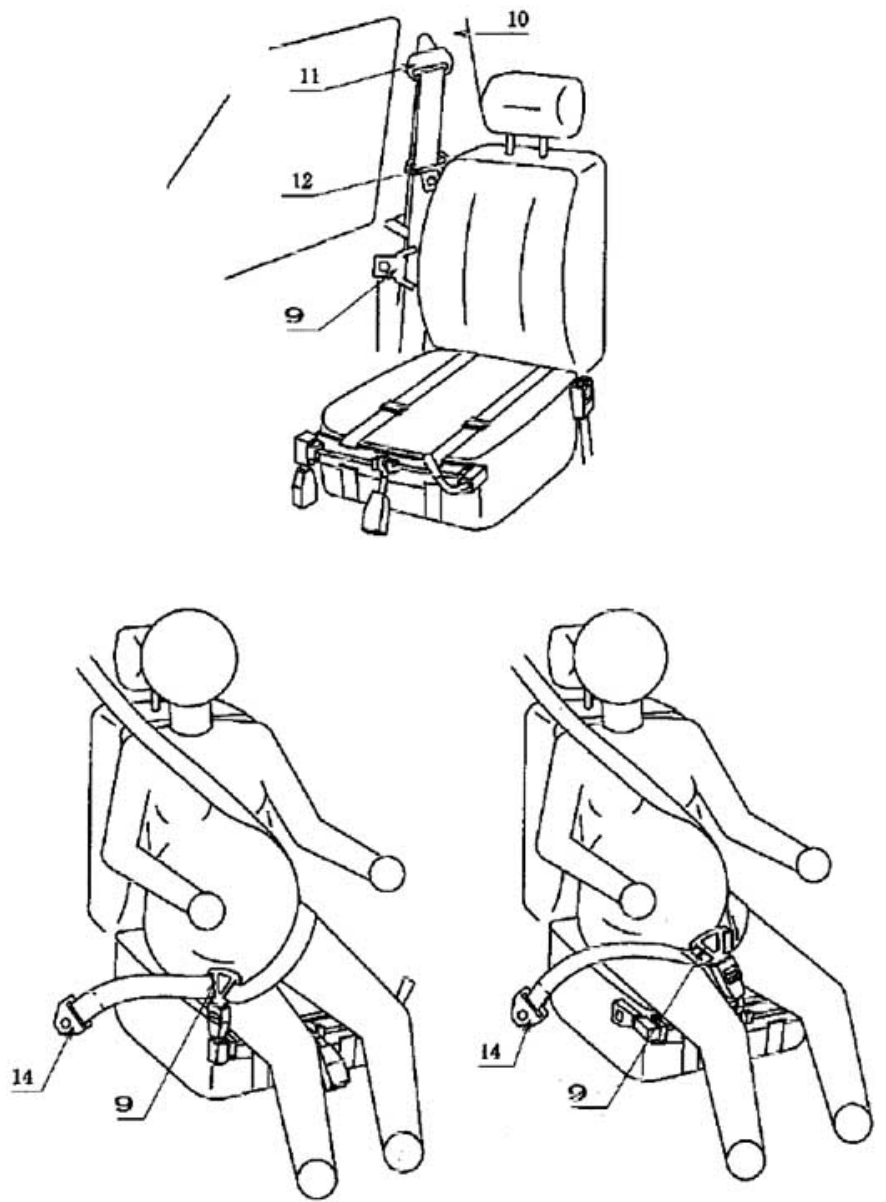

Fig. (5). Seat belt auxiliary device (for the complete description of the numbers, see [31]).
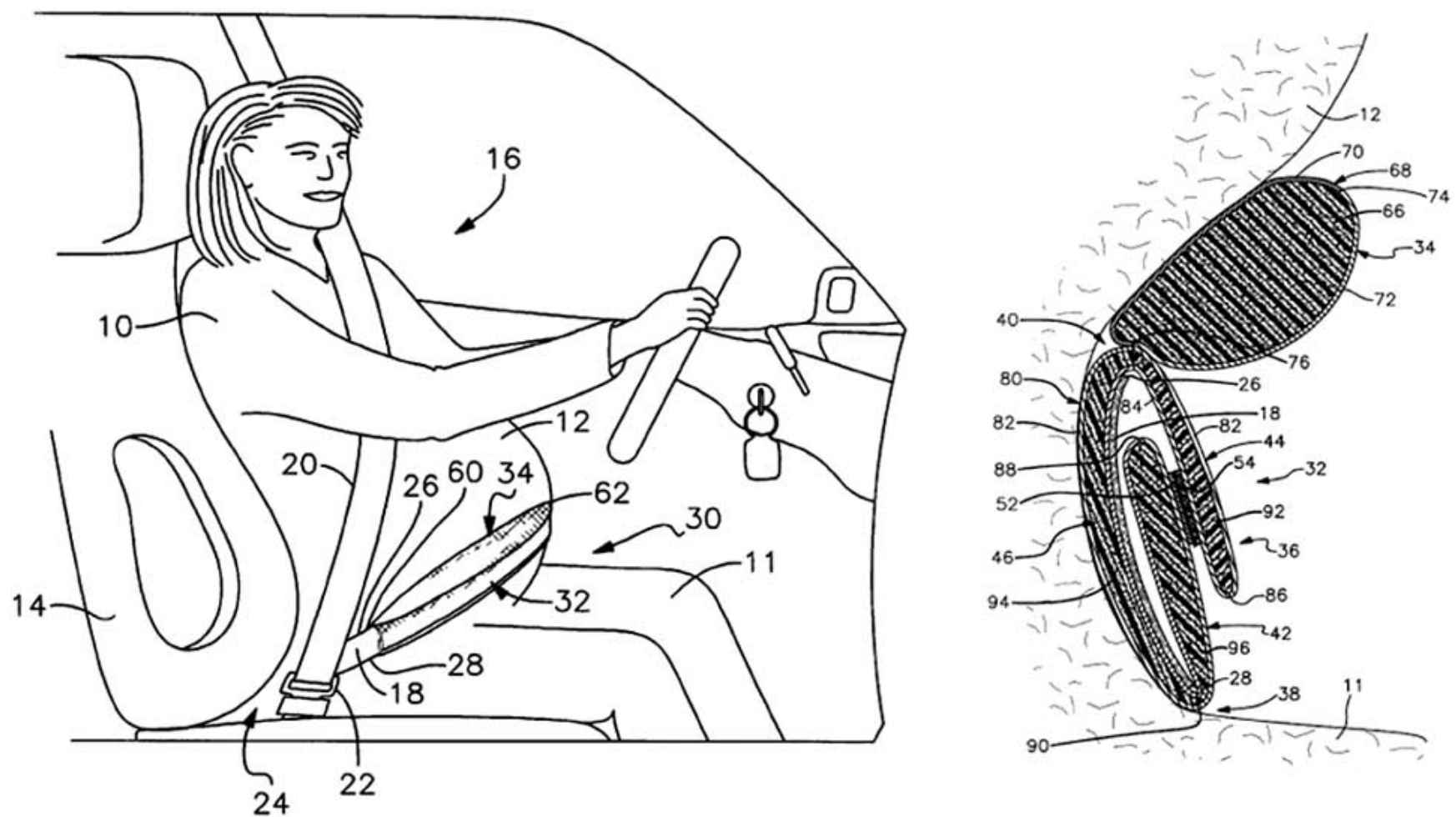

Fig. (6). Seat belt lap pillow and positioner (for the complete description of the numbers, see [32]). 
left and right side bones and the lap belt is attached from above the cushions [34]. The inventors claim that the abdominal oppression is reduced without relaxing the seat belt and the impact of the seat belt in the event of an accident is dispersed to the pelvis. Another concept by Takeaki and Yasuji in 2007 uses a rerouted pad for the rear passenger seats as fitted on the lap belt in order to stabilise the belt from riding towards the abdomen [35].

\subsubsection{Shoulder / Torso Supporting Designs}

There are fewer patents which are solely aimed at the shoulder belt than lap belt supporting designs. The design by Mitsuto in 2003 involves a safety device in the seat belt around the waist, which is fastened by a slip guide in a buckle part so that the impact during the accident is not applied to the seat belt around the waist but to the seat belt on the shoulder as shown in Fig. (7) [36]. As a result, the inventor claims that the upper half of the body of the pregnant woman is prevented from leaning forward excessively, protecting pregnant occupant's body and abdomen.
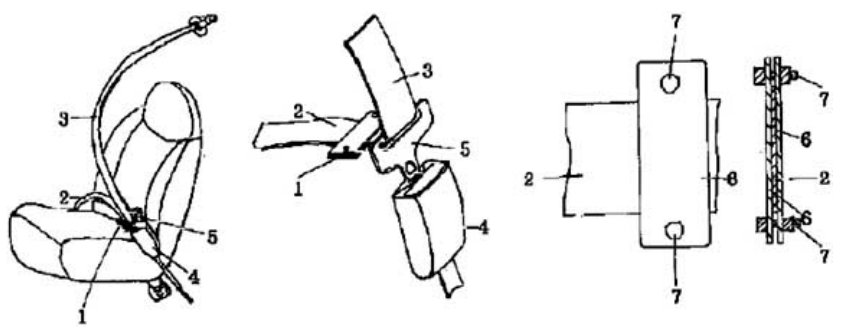

Fig. (7). Seat belt safety device (for the complete description of the numbers, see [36]).

Masayo patented an upper body fixture of seat belt for pregnant women in 2002, which comprises a harness with several buckles [37]. The inventor claims that the fixture is capable of fixing the body of the pregnant woman to the seat during movement on a vehicle.

\subsubsection{Combined Lap \& Shoulder / Abdomen Protecting Designs}

Combined lap and shoulder belt devices have also been designed and patented. Bohman and Haland developed a seatbelt fitting in 2004 for use by a pregnant woman, which comprises of a net attached by hook and loop style fastenings to the diagonal and lap portions of a three point seatbelt [38]. The fitting device is intended to reduce the pressure applied to the abdomen by the traditional 3-point seat belt. The fitting is designed to be attached directly to the shoulder and lap belts, as illustrated in Fig. (8), or looped around them and attached to itself. The inventors report that the fitting may comprise a hand inflated pad to cushion the pregnant occupant, and a further under seat restraint to maintain the lap portion of the belt in the correct position.

Weston designed a harness in 2006 for fitting around the body and the shoulder regions of the pregnant occupant, which is secured at the front of her torso by means of fasteners [39]. Before putting on the harness, the back portion is passed behind the oblique or diagonal portion of the standard
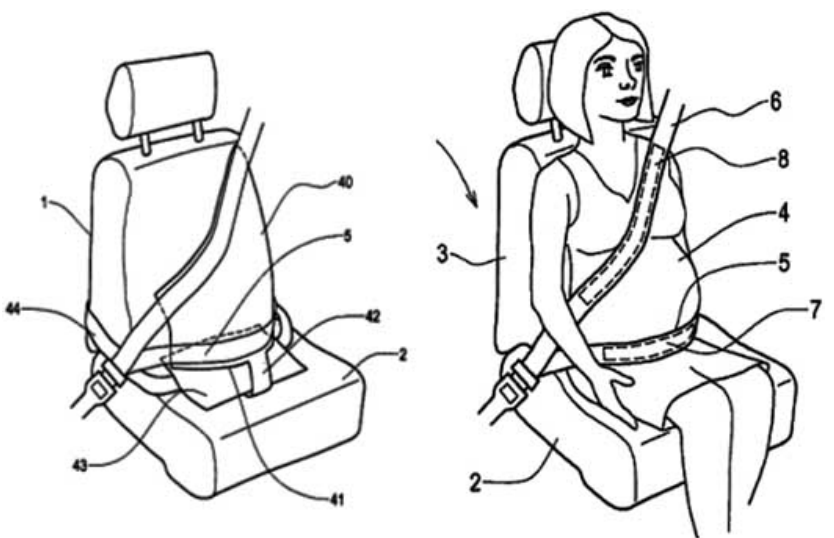

Fig. (8). Fitting for a seat belt (for the complete description of the numbers, see [38]).

seat belt as seen in Fig. (9). The inventor claims that any deceleration force to be taken up by the conventional 3-point seat belt via the harness, thus avoiding the discomfort usually caused when the shoulder belt extends in front of the wearer and the lower body of the wearer to be appropriately restrained by the conventional lap belt.

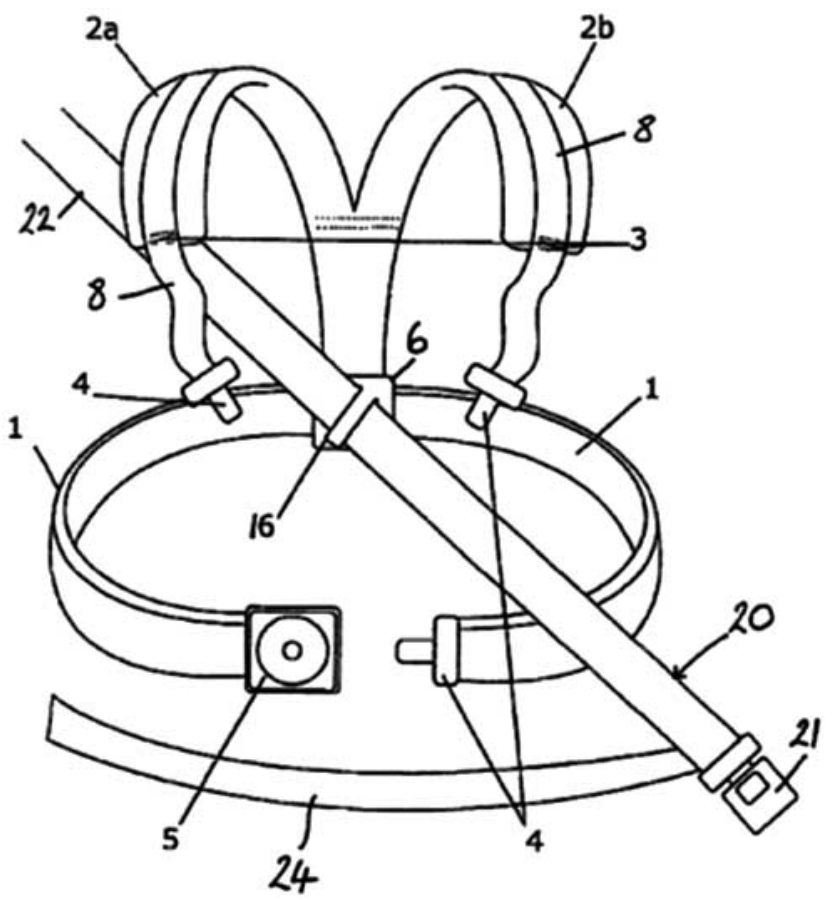

Fig. (9). Vehicle seat belt attachment for pregnant women (for the complete description of the numbers, see [39]).

A different design to protect the abdomen has been patented by Claudio in 1992 [40]. This concept used rigid elements as opposed to flexible textile materials as in the designs reviewed up to this point. The 'adjustable shield' for pregnant women comprises a reversed T-shaped body, the arms of which have adjustable fixing means with three comoving struts, the highest of which on a horizontal crossover padded support for the thorax and the lower two on respective divergent symmetrical padded supports, shaped 
for positioning in the folds of the groin Fig. (10). The author claims that the shield distributes the stress from the seat-belt throughout its length.

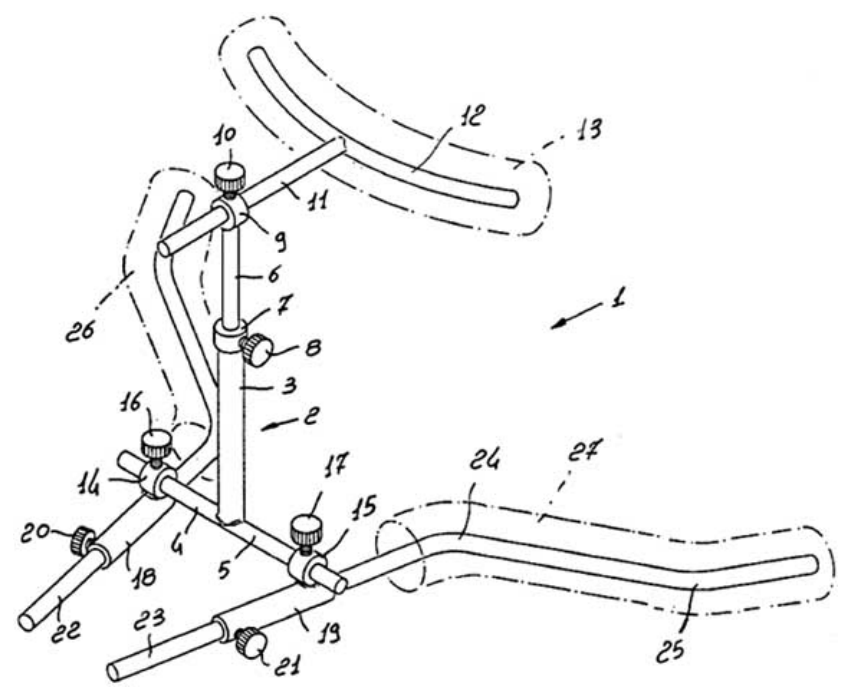

Fig. (10). Adjustable shield for pregnant women (for the complete description of the numbers, see [40]).

Ideas for protective cushion concepts are also used in this subgroup of designs. Huggins patented a reversible, detachable, protective pad in 2003, which can be attached to both shoulder and lap belts of the standard seat belt as illustrated in Fig. (11) [41]. A central cushion with tabs sewn into it forms the main part of the protective pad. The attachments of the pad to the standard seat belt portions are used via VELCRO hooks and loops. The pad cushion is designed to be manufactured from a moulded, soft to medium, rubber shell, encased with a spandex-type material on the outside. The inventor claims that the device is to be used as a protection means for pregnant occupants in automobiles, aircraft, and other vehicles.

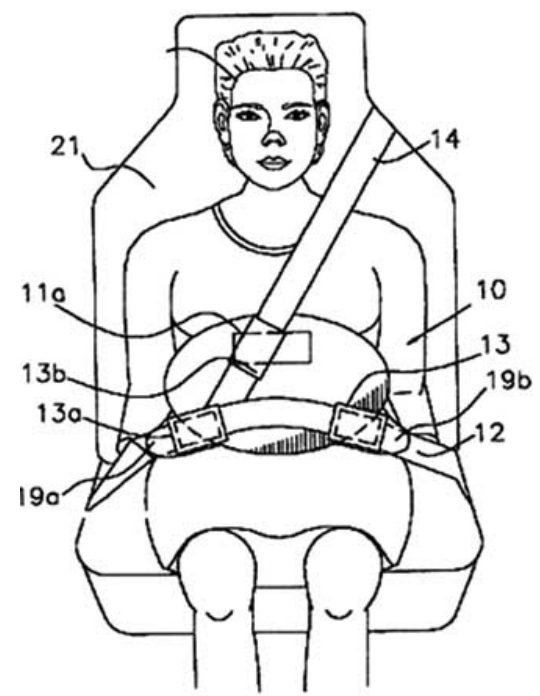

Fig. (11). Detachable protective pad for abdominal area (for the complete description of the numbers, see [41]).
Several other cushion type designs have been developed by other inventors [42-44], aiming at protecting the abdomen and using the standard 3-point seat belt.

A seat belt adapter has been designed [45] to engage the lap and shoulder belts at around the buckle, claiming that the device potentially reduces the injury risk during an impact situation.

\subsubsection{Other Auxiliary Solutions}

This group of solutions claims to offer safety and comfort to the pregnant occupant by aiming to improve various systems around the seat belt. For example the design has been patented by Grote in 1986, constitutes an adjustable seat belt-lifting claw that makes wearing the seat belt easy and avoiding constriction of the driver and front seat passenger in their seated position as in Fig. (12) [46]. With the seat belt-lifting claw located at the side, the seat belt is only at a very small distance from the body located in the seat. More recently, other examples for patented auxiliary systems include a seat belt warning device issuing an alarm when the person does not mount the seat belt [47] and a device for gripping the standard seat belt [48].

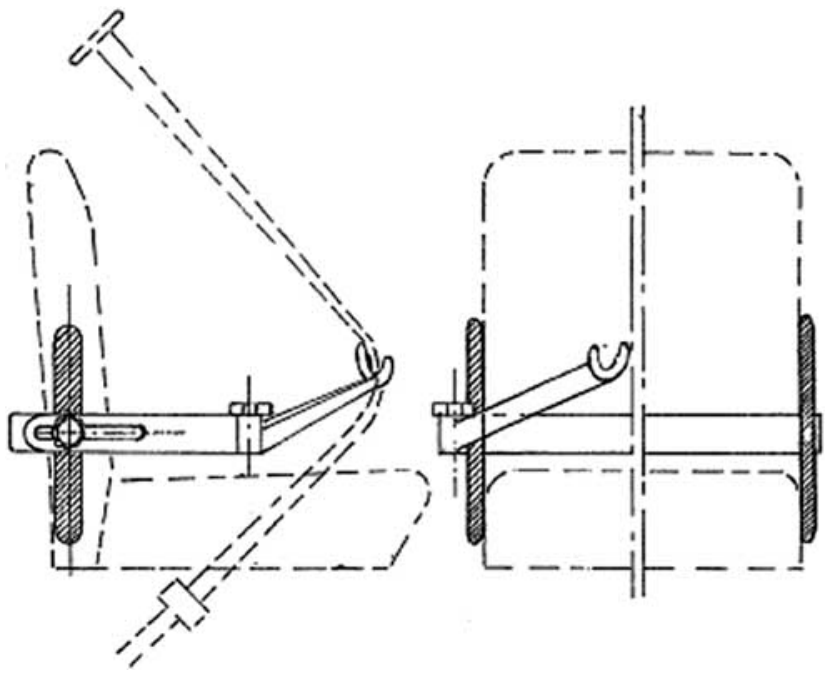

Fig. (12). Seat belt-lifting claw [46].

\subsection{Designs Excluding the Standard 3-Point Seat Belt}

The Designs Excluding the Standard Seat Belt group benefits from having much broader design possibilities, which probably originate from not having the design constraints imposed by the use of the standard 3-point seat belt at the centre of the solutions. Hence the ideas and designs in this group appear to be more diverse. The number of ideas patented in this group however appears to be considerably less than the number of ideas in the former group evolving around the standard seat belt.

Monagas developed a restraint system in 1996 for retaining the passenger relative to the automobile seat during deceleration of the vehicle as shown in Fig. (13) [49]. The harness system comprises of a pair of shoulder webs, which extend from behind the seat over respective left and right shoulders of the passenger to connect with a central web fastened at the forward edge of the seat. The inventor claims 


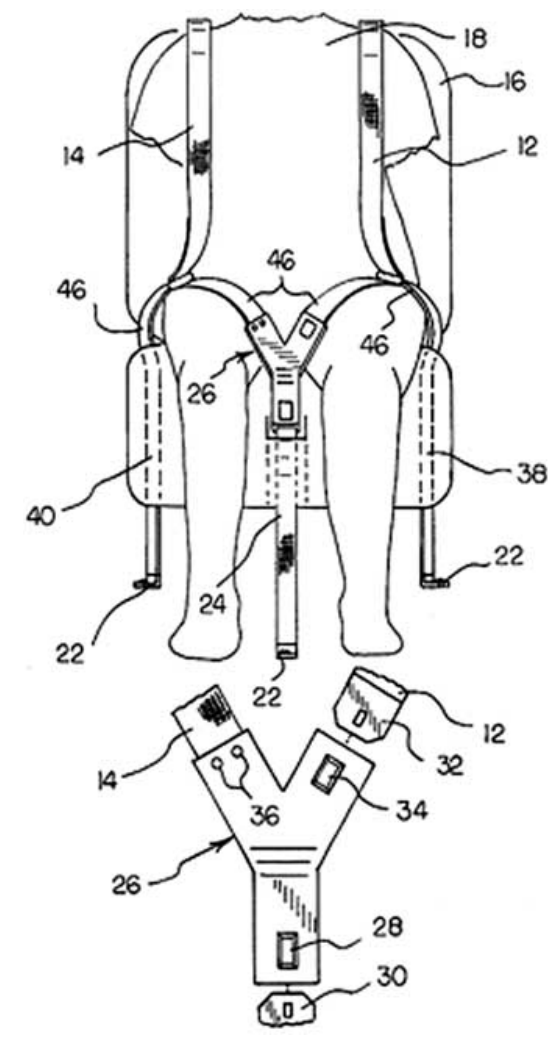

Fig. (13). Automobile restraint system (for the complete description of the numbers, see [49]).

that the system engages the upper anterior portions of the thighs and the shoulders of the passenger during deceleration, thereby precluding contact of the webs with the neck, chest, or central torso portions of the passenger.

Another complete seat belt system designed for pregnant women is patented by Wipper in 1994 [50]. The two-part safety belt system for pregnant women invention claims a belt-free zone for the abdomen and the breasts of the pregnant woman. The upper belt runs out from the belt retractor and the lower belt ends are screwed to standard fastening points of the vehicle as shown in Fig. (14). The central part of the lower belt lies on the seat pan. The front part runs via the groins of the pregnant woman whereas a second covering is additionally sewn on the seat back, under which the standard belt of the respective vehicle is present [50].

In 2006, Koichiro designed a seat belt device for pregnant women, and the solution involves rails for the seat, which are attached in the crash direction [51]. The system contains a webbing belt for the thighs, which is connected to both sides of the seat and restrains the lower half of the body of the passenger, and a belt at the front of the seat for the lower limb as illustrated in Fig. (15). Another example for seat belt solution for pregnant women is a lower limb fixture which restrains the whole lower body of the occupant as depicted in Fig. (16) [52].

Other examples include a separate shoulder belt design for pregnant women [53], a seat belt device which has a cross belt portion extending across the abdominal region [54], and a smart mechatronics seat belt system [55].

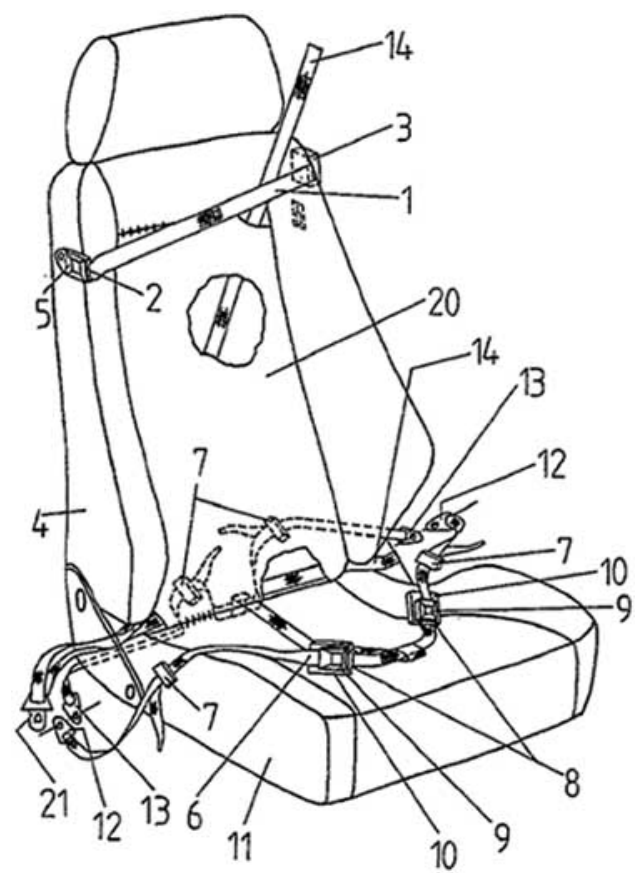

Fig. (14). Safety belt system for pregnant women (for the complete description of the numbers, see [50]).

\section{CONCLUDING REMARKS}

The review of patents for pregnant women in this article has shown that most of the designs develop around the standard 3-point seat belt, majority of which attempts to find a solution either for the lap belt alone or for the combined shoulder and lap belt system. This review has also revealed that many designs have been generated in the past thirty to forty years. The patents and patent applications range from simple add-on type solutions to complex harnesses, from simple mechanisms to advanced mechatronics applications. Some of the ideas evolved around the standard 3-point seat belt are manufactured and reached the market. On the other hand, the designs excluding the 3-point seat belt have not been marketed to date.

Characteristics of around forty patents are classified in this article. The authors believe that, ideally, a good design for pregnant woman should incorporate pregnant women's needs and characteristics, which are different than nonpregnant occupants [13]. It should also allow for a reasonable freedom of movement in the seat, whilst not compromising the additional safety features it brings about. It would have a clear commercial advantage if it is easy to use, cost-effective and it accommodates all sizes and shapes of pregnant women and all stages of pregnancy. It would be a bonus if it can also be used by non-pregnant people. The biomechanics criteria can be taken into consideration as highlighted in various pregnant occupant crash test dummy and computational modelling research [7, 8, 12-15]; to minimise the risk of injury, and in particular, placental abruption. The interactions of the proposed designs with the existing restraint systems such as frontal airbag or lap belt pretensioner can also be investigated in order to assess the safety, comfort, and robustness of the devices. 

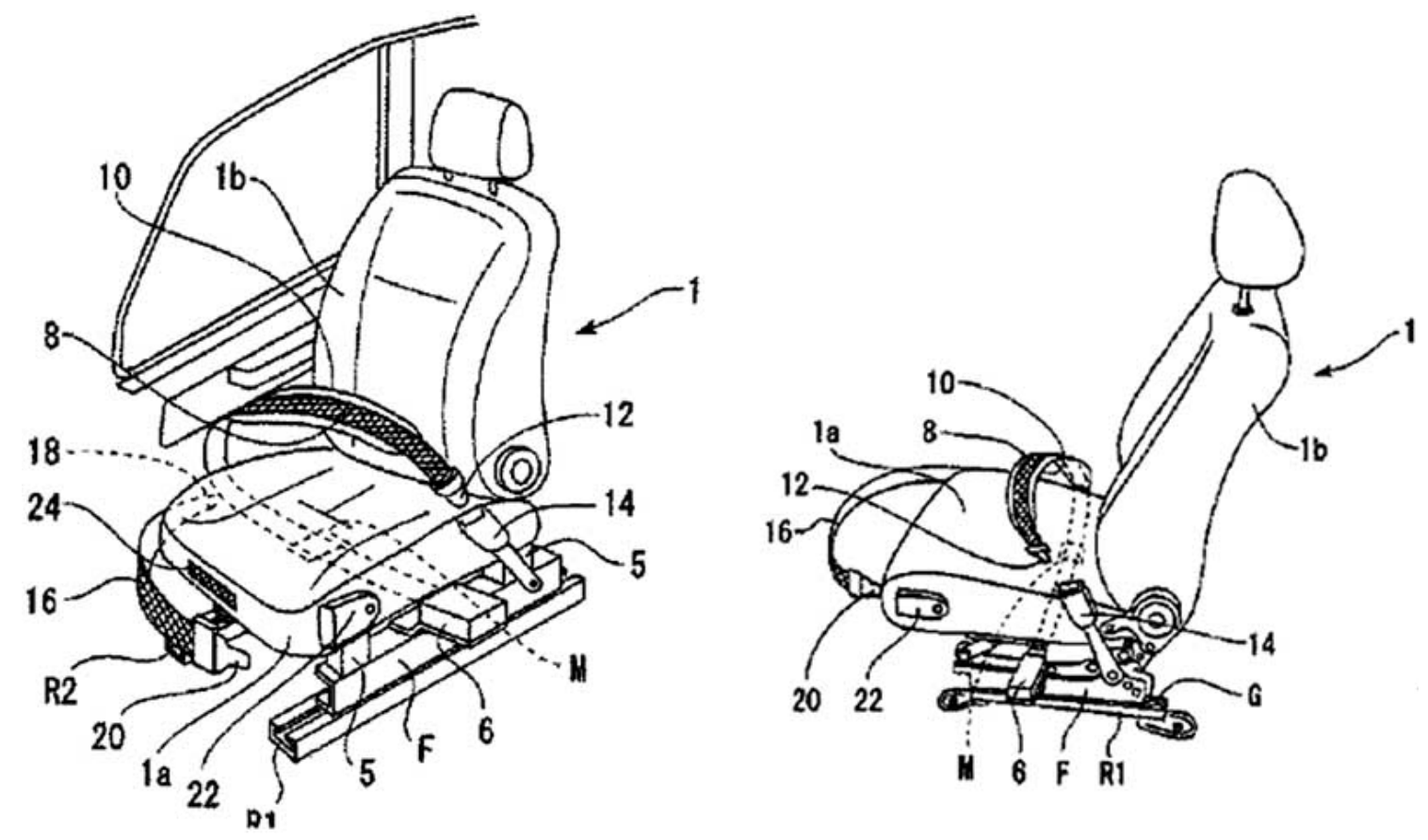

Fig. (15). Seat belt device (for the complete description of the numbers, see [51]).
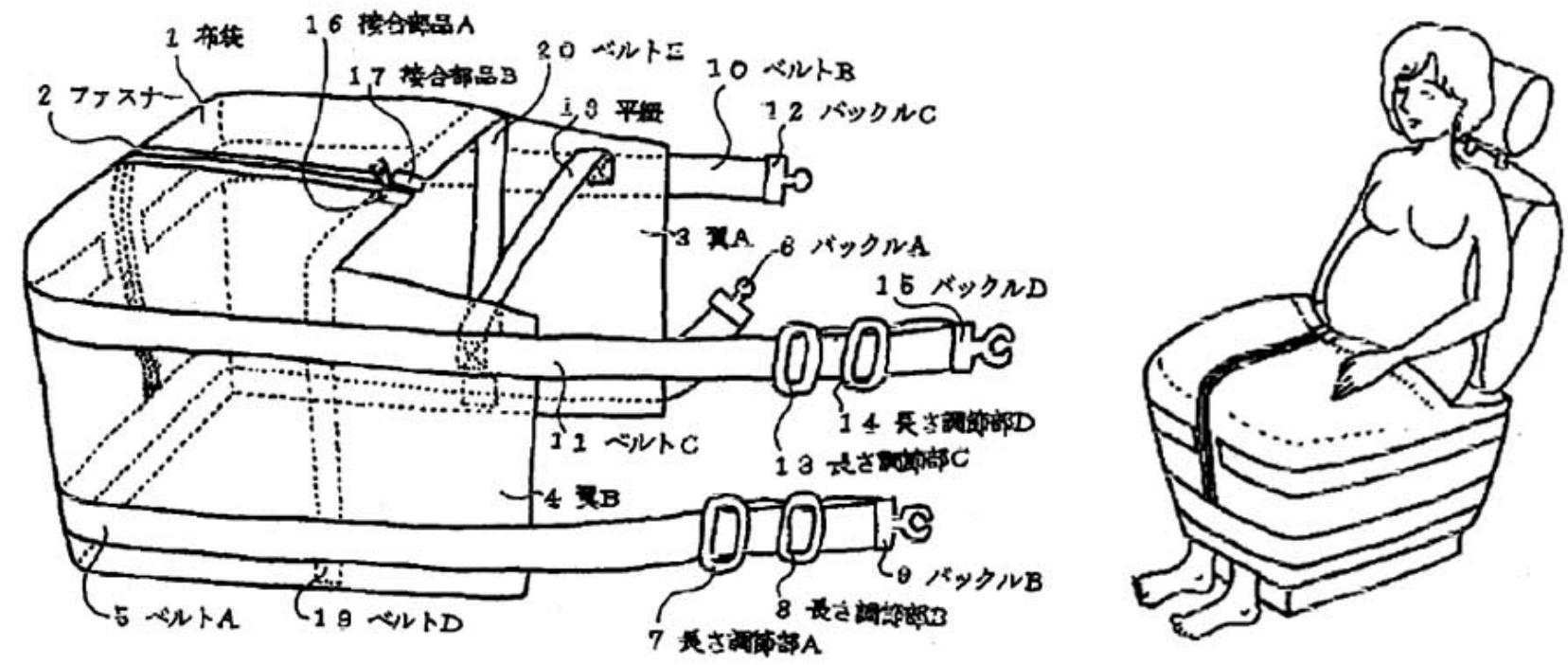

Fig. (16). Lower limb fixture for expectant mothers (for the complete description of the numbers, see [52]).

\section{CURRENT \& FUTURE DEVELOPMENTS}

The need for improved seat belt designs and devices for people who have difficulties in keeping the standard seat belt in its intended position, such as pregnant women, is an important topic in the biomechanics and injury prevention field. The global commercial potential for such products is huge. There are a few add-on safety devices for pregnant occupants in the market, which are similar to the patented ideas as summarised in 'Lap / Thighs Supporting Designs' section such as the design in [16]. No endorsement by the motor manufacturers has been found to date. It should not be surprising to see further designs to be patented and possibly commercialised in the near future.
The authors have also designed a conceptual seat belt device for pregnant women utilising their research findings of the comprehensive research in identifying the needs and characteristics of pregnant occupants and further computational modelling and simulation. The prototype was manufactured, tested by pregnant volunteers for comfort and the results appeared to be highly appealing and successful. The design is currently in the patenting process and will be disclosed when the patent has been filed.

\section{ACKNOWLEDGEMENTS}

This investigation took place as the first step of the 'Development of an Improved Seat Belt Design with Particular Emphasis on the Needs of Pregnant Women' 
project. The authors would like to thank the EPSRC (Engineering and Physical Research Council, UK) for funding the project under the Follow-on-Fund scheme.

\section{CONFLICT OF INTEREST}

At the time of writing, the authors are not related, commercially or otherwise, to the inventors of the patents reviewed in this article.

\section{REFERENCES}

[1] Haapaniemi P. Women's highway deaths on the rise. Traffic Safety 1996; 96: 6-11.

[2] Pearlman MD. Motor vehicle crashes, pregnancy loss, and preterm labor. Int J Gynecol Obstet 1997; 57(2): 127-132.

[3] Weiss HB. The epidemiology of traumatic injury-related fetal mortality in Pennsylvania, 1995-1997. The role of motor vehicle crashes. Accid Anal Prev 2001; 33: 449-454.

[4] Birth Statistics - Review of the registrar general on births and patterns of family building in England and Wales. Office for National Statistics 2007; Series FM1 No. 35.

[5] Births in Scotland - High Level Summary of Statistics Trend, GROS Registration Data. The Scottish Government, Statistics, October 2007.

[6] Statistics Press Notice - Births in Northern Ireland. NISRA, March 2007.

[7] Klinich KD, Schneider LW, Rupp JD, Eby B, Pearlman MD. Investigation of crashes involving pregnant occupants. Report UMTRI-99-200, 1999.

[8] Pearlman MD, Viano DC. Automobile crash simulation with the first pregnant crash test dummy. Am J Obstet Gynecol 1996; 175(4): 977-981.

[9] Bunai Y, Nagai A, Nakamura I, Ohya I. Fetal death from abruption placentae associated with incorrect use of a seat belt. Am J Forensic Med Pathology 2000; 21(3): 207-209.

[10] Crosby WM, Snyder RG, Snow CC, Hanson PG. Impact injuries in pregnancy. Am J Obstet Gynecol 1968; 101(1): 100-110.

[11] Viano D, Jedrzejczak E, Deng B, Smrcka J, Kempf P, Pearlman M. Belt and airbag testing with a pregnant hybrid III dummy. J Traffic Med 1996; 26(3-4): 125-138.

[12] Acar BS, Weekes AM. Designing for safety during pregnancy through a system for automotive engineers. Int J Crash 2004; 9(6): 625-631.

[13] DfT Website. 'Think!' Road Safety Advice. www.dft.gov.uk/ think_media/241045/241136/buckleup.pdf
[14] Acar BS, Weekes AM. Design guidelines for pregnant occupant safety. Proc IMechE Part D. J Automobile Eng 2005; 219: 857867.

[15] Acar BS, Van Lopik D. Computational pregnant occupant model, 'Expecting', for crash simulations. Proc IMechE Part DJ Automobile Eng 2009; 223: 891-902.

[16] Kruse, S.: US5005865 (1991).

[17] McGlothlin, M.D., Fagan, C.J.: US5624136 (1997).

[18] Nerette, S.: US6935700 (2005).

[19] Zlojutro, M.: US7270347 (2007).

[20] Arditi, Y., Goldchmit, C.: US20020140279 (2002).

[21] Rosemary, M.J.: EP1193143 (2002).

[22] Xu, Z.: US20040051294 (2004).

[23] Herrmann, M.: US6517163 (2003).

[24] Noboru, M.: JP2003226224(2003).

[25] Takeaki, K., Takeshi, Y.: JP2006103400 (2006).

[26] Takeaki, K., Takeshi, Y.: JP2006103549 (2006).

[27] Yoshihiro, A.: JP63222956 (1988).

[28] Takeshi, Y., Masaichi, C.: JP2005153551 (2005).

[29]

[30]

[31]

[32]

[33]

[34]

[35]

$[36]$

[37]

[38]

[39]

[40]

[41]

[42]

[43]

Tatsuya, K.: JP2005199900 (2005).

Korneliussen, K.: US5257854 (1993).

Tsutomu, I.: JP2002347571 (2002).

Harper, C., Benson, J.J., McComb, H.: US6352150 (2001).

Von Bergen, K.: DE10216204 (2003).

Akihiro, S., Jun, W.: JP2006103447 (2006).

Takeaki, K., Yasuji, I.: JP2007090903 (2007).

Mitsuto, F.: JP2003212082 (2003).

Masayo, T.: JP2002029374 (2002).

Bohman, K., Haland, Y.: GB2402653 (2004).

Weston, W.S.: GB2423057 (2006).

Claudio, L.: IT1235587 (1992).

Huggins, B.B.: US20030052528 (2003).

Jellife, R.S.: GB1415991 (1975).

Efrom, H.: WO8707569 (1987).

Yasumitsu, T.: JP2005145391 (2005).

Shoshana, O., Roni, G., Zafrira, W.: CA2174693 (1997).

Grote, G.: DE3435678 (1986).

Masahiro, T., Hiroyuki, I., Shoichi, Y.: JP2004026030 (2004).

Drinkrow, R.J.: US7036849 (2006).

Monagas, G.: US5524928 (1996).

Wipper, A.: DE4411247 (1994).

Koichiro, Y.: JP2006273167 (2006)

Masayo, T.: JP2002029373 (2002).

Wipper, A.: DE4412805 (1994).

Mayumi, T.: JP2003200815 (2003).

[55] Tabe, J.A.: US6728616 (2004). 